\title{
Como periódicos científicos em fisioterapia podem auxiliar a tratar as assimetrias regionais
}

\section{How scientific journals in physiotherapy can fix regional asymmetries}

\section{Katia Nunes Sá ${ }^{\text {, Cristiane Maria Carvalho Costa Dias }}{ }^{2}$}

'Escola Bahiana de Medicina e Saúde Pública. ORCID: 0000-0002-0255-4379. katia.sa@bahiana.edu.br ${ }^{2}$ Escola Bahiana de Medicina e Saúde Pública. ORCID: 0000-0003-1944-3154. cmccdias@bahiana.edu.br

Com o desenvolvimento das ciências da informação e da comunicação nas últimas décadas, a velocidade com que ocorre a disseminação do conhecimento científico, se elevou substancialmente'. Este processo vem impulsionando as ciências contemporâneas da saúde ao desenvolvimento de práticas clínicas baseadas em evidências científicas, a uma maior acurácia do diagnóstico e aos melhores resultados das condutas aplicadas².

Historicamente, a fisioterapia, cujos profissionais há apenas um século ainda eram confundidos com massagistas e profissionais do $\mathrm{sexo}^{3}$, não cabia o reconhecimento como ciência pelo senso comum. Talvez, justamente por esta marca, fisioterapeutas lutaram com afinco para serem reconhecidos por seu domínio científico sobre o tratamento das disfunções do movimento, ainda que muitos ainda não conheçam profundamente - que significa uma verdadeira prática baseada em evidências ${ }^{4}$. Há menos de 50 anos ela foi regulamentada no Brasil como profissão da saúde de nível superior e seu desenvolvimento foi predominantemente empírico, só se impulsionando como ciência a partir da criação do primeiro mestrado em $1996^{5}$. Apesar do pouco tempo de criação de programas de pós-graduação stricto sensu para o desenvolvimento da ciência da fisioterapia, as pesquisas científicas brasileiras na área são cada vez mais qualificadas e reconhecidas pelos outros profissionais da saúde em nível mundial ${ }^{3,4}$.

No entanto, as métricas estabelecidas pela Coordenação de Aperfeiçoamento do Pessoal de Nível Superior (CAPES) vêm induzindo movimentos por parte dos pesquisadores que dificultam a visibilidade dos resultados das pesquisas ${ }^{6}$. Para atingir os pontos necessários para o credenciamento e recredenciamento em programas de pós-graduação, fisioterapeutas docentes permanentes não podem publicar em periódicos específicos, em português, que são mais visíveis para os fisioterapeutas e para a população brasileira. Publicam os achados de suas pesquisas em revistas de medicina e áreas afins pelo longo tempo de existência e, por isso mesmo, seu elevado fator de impacto 7 . Das 42 revistas no tema da fisioterapia e reabilitação do primeiro quartil que constam do ranking SJR com fator de impacto (FI) acima de 0,786 (acesso em 29/01/2018 disponível em http://www.scimagojr.com/ journalrank. php? category $=3612$ ), 20 são norte americanas, 18 são inglesas, 2 são 
australianas, 1 é italiana e 1 é turca. Das 169 ranqueadas, $\circ$ American Journal of Sports Medicine ocupa o topo do ranking com fator de impacto de 3,375 e a Revista Brasileira de Fisioterapia ocupa a $70^{a}$ posição com um fator de impacto de 0,521 .

O pequeno número de periódicos indexados que permite aos docentes pontuarem nas métricas do sistema Qualis da CAPES, os conflitos de interesse envolvidos com o processo de avaliação dos artigos (competição entre grupos de pesquisa, vaidade dos pesquisadores, maior chance de citação e possibilidade de ganhos diretos ou indiretos com as publicações)' ${ }^{1}$ e os crescentes custos para publicações, dificultam significativamente que os resultados das pesquisas alcancem o público alvo ${ }^{8}$. Por este motivo, a sociedade que, em última instância, é quem financia as pesquisas, não consegue acesso aos resultados de todas as pesquisas científicas realizadas. Além disso, muitas editoras e revistas científicas predatórias se aproveitam das metas estabelecidas pelos órgãos de regulamentação da ciência para assediar pesquisadores a publicarem em seus periódicos que muitas vezes desaparecem de circulação no segundo ou terceiro volume?. Neste cenário, fica cada dia mais difícil que a população envolvida como participante dos estudos, financiadores de insumos e equipamentos, e os próprios pesquisadores tenham acesso ao conhecimento ${ }^{10}$.

Com taxas de rejeição da ordem de $80 \%$, custos com tradução e publicação com média de 2.000 dólares por artigo e sem financiamento adequado', as revistas qualificadas existentes não conseguem atender às demandas de divulgação do conhecimento produzido em fisioterapia. Estes dados demonstram que a pesquisa em fisioterapia publicada corresponde a $20 \%$ do que é submetido por uma elite que consegue financiamento para publicação, segregando pesquisas realizadas por aqueles que não têm os mesmos recursos. Isto não significa que não existem pesquisas qualificadas desenvolvidas em instituições de ensino e pesquisa em regiões mais pobres, mas significa sim que os resultados destas pesquisas não podem se tornar públicos.

A despeito da real necessidade da criação de novos periódicos, avaliadores dos sistemas de indexação (LILACS, SciELO e Pubmed), dos rankings de citação (SJR e Citefactor) e do Sistema Qualis
(CAPES) aumentam progressivamente as exigências com o objetivo de atingir $\circ$ padrão internacional e de garantir o desenvolvimento e a qualidade das publicações ${ }^{5,6}$. Por isto, torna-se cada vez mais difícil que um periódico novo consiga se desenvolver neste cenário". As poucas revistas em fisioterapia indexadas nas diferentes bases deveriam se unir para cooperarem entre si, não para descumprir os princípios da integridade científica ${ }^{12}$, mas para que a profissão como fim comum possa se desenvolver ainda mais e que o mundo possa conhecer os relatos dos estudos feitos em regiões menos privilegiadas que sofrem com problemas de saúde específicos. Somente deste modo se pode começar a tratar as assimetrias regionais da ciência em fisioterapia no Brasil e no mundo.

\section{Referências}

1. Packer AL. Os periódicos brasileiros e a comunicação da pesquisa nacional. Rev USP. 2011 ;89:26-61. doi: 10.11606/ issn.2316-9036.v0i89p26-61

2. Brownson RC, Baker EA, Deshpande AD, Gillespie KN. Evidence-Based Public Health. 3.ed. Montreal: Oxford; 2017.

3. Peseta T, Fortune T, Jones A, Barradell S, KennnedyJones $M$. Returning history to the educational formation of health professionals in Australia. Teaching in Higher Education. 23(1):17-29, 2017. doi: $10.1080 / 13562517.2017 .1340267$

4. Silva TM, Costa LCM, Costa LOP. Evidence-Based Practice: a survey regarding behavior, knowledge, skills, resources, opinions and perceived barriers of Brazilian physical therapists from São Paulo state. Braz J Phys Ther. 19(4):294303. doi: 10.1590/bipt-rbf.2014.0102

5. Cavalcante CCL, Rodrigues ARS, Dadalto TV, da Silva EB. Evolução científica da fisioterapia em 40 anos de profissão. Fisioter Mov. 2011 ;24(3):513-22. doi: 10.1590/S0103$\underline{51502011000300016}$

6. Nigro CA, Ferraz RRN, Quoniam L, Alves WAL, Messias LRR. Prestação de contas anual e quadrienal à Capes por um programa de pós-graduação stricto sensu em engenharia de produção: utilização da ferramenta computacional Scriptlattes-Scriptsucupira. Prisma.Com. 2015; 29:3-26.

7. Paci M, Landi N, Briganti G, Lombardi B. Factors associated with citation rate of randomised controlled trials in physiotherapy. Arch Physiother. 2015;5:9. doi: 10.1186/ s40945-015-0009-6 
8. Van Noorden R. The true cost of science publication. Nature. 2013, 495(7442):426-429. doi: 10.1038/495426a

9. Manca A, Martinez G, Cugusi L, Dragone D, Mercuro

$G$, Deriu F. Predatory open access in rehabilitation. Arch Phys Med Rehabil. 2017;98(5):1051-6. doi: 10.1016/i. apmr.2017.01.002

10. Kellner AWA. Editors of Brazilian journals - a hard life that is getting harder! An Acad Bras Cienc. 2017;89(1):1-2. doi: $10.1590 / 0001-37652017891$

11. Sá KN, Dias CMCC, Segundo JDB. Critérios para a consolidação de um periódico de pesquisa científica em fisioterapia. Rev Pesq Fisio. 2016;6(3):317-340. doi: $10.17267 / 2238-2704$ rpf.v6i3.1028

12. Vasconcelos $S M R$, Sorenson $M M$, Watanabe $E H$, Foguel $D$, Palácios M. Brazilian Science and Research Integrity: Where are We? What Next? An Acad Bras Cienc. 2015; 87(2): 1259-1 269. doi: 10.1590/0001-3765201520150165 